\title{
The construction and application of the unit curtain wall system of the steel-aluminum combination
}

\author{
Lu Tong ${ }^{1}$, Wang Shuai ${ }^{1 *}$, Li Wenxiang ${ }^{1}$, Luo Le ${ }^{2}$, Huang Shiqi ${ }^{2}$, Fu Qinyou ${ }^{1}$, Xiong Wenhui ${ }^{1}$ \\ ${ }^{1}$ Wuhan Construction Group Co., Ltd. Enterprise Technology Center, 430056 Wuhan, Hubei \\ ${ }^{2}$ Wuhan University of Science and Technology, School of Urban Construction, 430065 Wuhan, Hubei
}

\begin{abstract}
Curtain walls are widely used in the epidermis of buildings. At present, the unit curtain wall system production frame is mainly aluminum profile. But taking into account the weak aluminum strength and soft characteristics, the existing curtain wall often ensure the frame carrying capacity by increasing the amount of aluminum per unit area, which makes the high curtain wall costs. At the same time, the nodes of its production process are complex and require higher functions of production equipment. In this paper, a unit curtain wall system of steel-aluminum combination is proposed, which has the characteristics of simple construction, processing and installation, consisting of three key technologies including new steel-aluminum material combined with keel frame technology, glass curtain wall installation technology and cross-stitch node waterproofing technology. The system (1) in the construction, the integration of the concept of just soft. The unit structure of "steel column and aluminum profile" plays an advantage of high steel structure strength to ensure carrying capacity. In addition, the aluminum profile is fully plastic and the shape can be controlled. (2) In the production mode, the unit curtain wall is prefabricated by factory flow watering, and the processes are independent of each other, which is convenient for organizing processing equipment. (3) In the installation, the roof ring track and hoist are used to lift the unit plate, which avoids adverse shaking and rotation, reduces the risk of high-altitude operation and shortens the duration. This technology is of great reference significance to the construction of curtain wall of high rise buildings.
\end{abstract}

\section{Introduction}

Curtain wall, defined as thin and bordered wall, is a kind of decorative wall suspended on the building structure through keel, which does not bear the load of building floor or roof ${ }^{[1-2]}$. Currently, unit curtain wall systems typically use aluminum as a frame for production, but the heavy use of aluminum can lead to higher costs. In order to reduce the use of aluminum, Tai Deliang ${ }^{[3]}$ optimized the aluminum frame and found that when aluminum alloy is used, the amount of aluminum meetingmeet the bearing capacity is still very large and the cost is still very high. Hong Lixiang ${ }^{[4]}$, pointed out that there are many difficulties in the curtain wall installation process such as the processing accuracy of the plate itself, preburied parts of the installation, transfer parts of the installation and lightning connectionare the difficulties in. Liu Yonghua ${ }^{[5]}$ proposed a method to improve the design of frame curtain wall keel connection nodes, realizing the unit assembly installation of the frame curtain wall keel, which can speed up the construction progress. Bian Jing Quan $^{[6]}$ analyzed the design and materialsdand summarized the principle of waterproofing and the cause of water leakage, puting forward to the importance of curtain wall waterproofing. It is not difficult to see that the previous research is mainly by optimizing the form of aluminum frame to improve the framework. However, the low strength of aluminum makes the frame structure can not be effectively improved, which also makes the processing and assembly of the frame difficult. In addition, curtain walls are used in high rise buildings, which often need to be installed on high altitude conditions. In the curtain wall installation technology, previous studies on curtain wall installation technology are relatively few to ensure installation accuracy and construction safety. At the same time, because the curtain wall is more of a unit installation, and the external environment in the process of contact, need to consider rain, snow and so on for the penetration of the curtain wall, so the curtain wall waterproof technology research is also very important, and this aspect of the study is not deep enough. It is an important research topic to optimize and innovate the structure, assembly form, installation process, waterproofing technology and so on, which will greatly improve the life of curtain wall and meet the increasing demand for curtain wall construction and engineering construction. In this paper, the frame materials have been innovated and the structure, production and installation of the traditional curtain wall, waterproof technology has been optimized combined with the actual needs of the project. A unit-type glass curtain wall new steel aluminum combined with keel frame technology, to achieve the balance between

\footnotetext{
"Corresponding author: 356797825@qq.com
} 
strength and control modeling, in order to meet the carrying capacity of the curtain wall system, can effectively reduce the use of aluminum, improve frame stiffness, reduce the cost of use. The simple production process and the higher precision, which improve the speed and precision of construction, guarantee the overall waterproof performance of the curtain wall. The reduction of gap between curtain wall unit plates improves the overall tightness. In addition, owing to the cross stitching node waterproof technology, curtain wall stitching node can ensure good water resistance. Actually, the project has been successfully used in Wuhan Construction Science and Technology Center building.

\section{Engineering overview}

Wuhan Construction Science and Technology Center Building, located in Wuhan City, Hubei Province, Caidian District Chaoyang Avenue, has the total land use area of $13714.22 \mathrm{~m}^{2}$, the total construction area is $84646.8 \mathrm{~m}^{2}$. The basement is a 3-storey building area of $28374.32 \mathrm{~m}^{2}$ (single floor approx. $9458 \mathrm{~m}^{2}$ ) for equipment rooms and garages, and the above-ground floor area of $56193.69 \mathrm{~m}^{2}$ consists of 31-storey towers and 5-storey podiums with commercial, conference, catering, office, scientific and other functions. With a structural surface height of $137.70 \mathrm{~m}$ and a building height of $149.0 \mathrm{~m}$, it features a unit-based glass curtain wall with a total of 3406 blocks spread over four facades in the east, south, west and north of the tower. This product is composed of three key technologies: new steel-aluminum material combined with keel frame technology, glass curtain wall installation technology and cross-stitch node waterproofing technology, which is a unit curtain wall system with a combination of steel and aluminum.

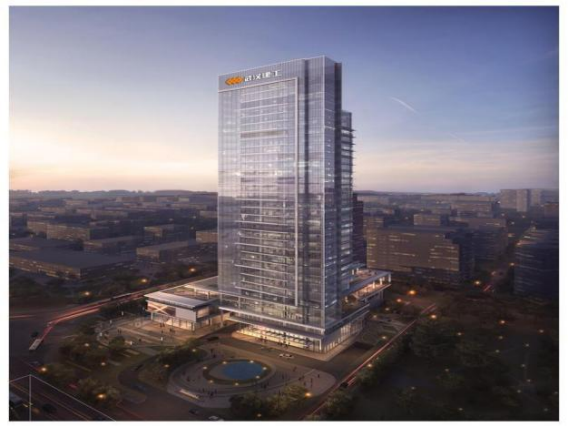

Fig. 1. Steel aluminum curtain wall Engineering application effect

\section{Steel aluminum combined with keel frame technology}

As the main force structure of the unit plate, the steel column and aluminum sub-frame are made of stainless steel self-tapping nails into a combined column, and then the slotted aluminum core is fixed to the combined column. The aluminum profile beam cavity and the core are plugged in, the upper and lower directions are fixed by the self-tapping nail, and the combined column is assembled into a keel frame ${ }^{[7-8]}$. The entire technology is mainly the production and assembly process of frame structure and unit curtain wall system. The skeleton consists of a pair of steel-aluminum composite columns and three aluminum beams with different sections. The steel-aluminum composite is inserted through the slot aluminum to avoid additional processing, reducing the use of equi-pment and improving production efficiency ${ }^{[9]}$.

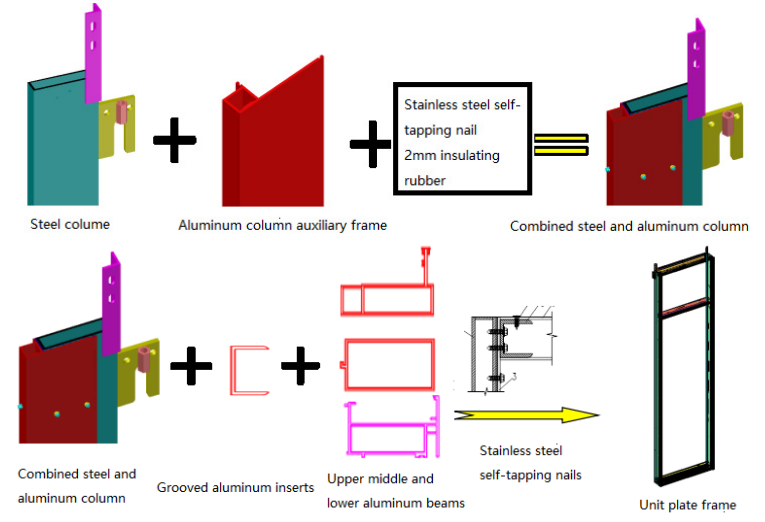

Fig.2. Steel-aluminum combination column indication

In order to adjust the unit body according to the field conditions to meet different needs, special position corners and grooves are not made of standard unit plates, but take advantage of the ease and strength of steel structure stitching. According to the special-shaped steel keel matching the architectural modeling design and engineering practice, the aluminum profile and special steel keel are combined to form an overall strength structure. The main area of the alien unit body and the standard unit body is that the structure of galvanized steel keel is inconsistent.

\subsection{Production and assembly of curtain wall systems}

Through the deepening of the design, a map and a general table are made. The double-head saw is used to cut the aluminum profile materials, and hydraulic equipment is used to punch the lower beam, to produce the engineering technology products.

In the production of steel columns, two $10 \mathrm{~mm}$ holes are opened at the established position below the steel column, and the stainless steel rivet nut is fixed on the hole, so that when connecting the upper and lower plates on site, the M8 sink bolt can be used to pass through the angle steel oval hole and screwed into the steel rivet nut, and the upper and lower plate columns are fixed through vertical angle steel. For the special plate connection, the steel structure is used to control the shape, which can play the role of carrying.

When assembling the frame, the steel-aluminum combined column processing using a "snapable" clamping film, the tire film has the following points:

(1) According to the general plate length, the tire film is fixed at both ends of the top tight angle aluminum.

(2) The upper cover plate rotates the compression combination column through the hem, and the combined column is fixed in the tire membrane by using the 
auxiliary top-tightening device to form the combined column.

(3) According to the general plate on, middle and lower beam size to determine the slotted aluminum core position, push back the length of the two upper cover plate, reserve slot aluminum installation gap, installation slot aluminum process can be easily positioned without repeated measurement.

(4) A lateral spacing of $50 \mathrm{mmis}$ reserved on the upper coverplate, with a vertical spacing of @ $350 \mathrm{~mm}$ a round hole with an aperture of $10 \mathrm{~mm}$, as the reference point for the installation of self-tapping nails, drilling and tapping without repeated positioning.

After the frame assembly is bonded to the glass, the glass specification used in this engineering unit plate is 6 -1.14pvb-6 (Low-E) and 12A-8 ultra-white hollow sandwich double silver tempered glass, and the twocomponent silicone neutral structure glue is used. In order to ensure the effect, the process of quality control is very important in the implementation process. Vertical fasteners are installed in two steps:

(1) Install the side injection glue baffle, fix on the aluminum frame, add a long EPDM adhesive strip between the baffle and the glass, extrusion adhesive strip to ensure air tightness, avoid direct contact between hard materials and glass.

(2) Install the outer cover plate. The outer surface of the outer cover plate is coated with fluorocarbon, which is corrosion-resistant and UV-resistant; The edge is clamped through a double bayonet, and the contact position of the glass is added with EPDM rubber strip matched with the bayonet, and the outer cover plate is made firmer by extrusion.

After the plate is formed, someone is arranged to inspect the plate quality, and deal with 4 problems at the same time:

(1) The lower beam waterproof rubber strip penetrates into the groove and the outer side of the buckle strip is worn with the adhesive strip.

(2) The upper and lower mouths of the steel column are sealed with open-mold rubber strips to prevent water vapor from entering.

(3) Close the gap positions at both ends of the fastener with weather-resistant sealant.

(4) The product is classified and stacked, and the self-made removable and reversible activity frame is transferred with the forklift.

\section{Unit glass curtain wall installation technology}

After lifting, hanging glue and other processes, the application of production and assembly completed curtain wall system can be applied.

\subsection{Lifting process}

The hoisting equipment shall be installed before the plate hoisting. The unit plate of this project adopts the vertical transportation hoist, and the horizontal hoist is used for hoisting on the roof circular track.
The installation techniques involved have the following advantages:

(1) The fast speed and long travel of the holizer are more efficient for vertical transportation of the $149 \mathrm{~m}$ height unit plate in this project.

(2) The lifting speed of electric hoist is slow. It can move horizontally, and lifting plate is safer and more convenient.

The holizer is fixed on the roof and changes the traction direction of the equipment by setting the sheave as a vertical transportation device for the unit plate. The roof ring rail assembly frame is installed at the edge of the roof. The track uses I18 word steel, through highstrength bolts to secure its upper wing edge on the construction beam, and then the electric hoistis edinstall and commissioning can be used normally.

When lifting, the roof lifting control plate is transported vertically first, and the lifting process and the ropeway rise smoothly. When transported to the installation workshop, the unit plate is installed using the electric hoist traction on the roof ring track.

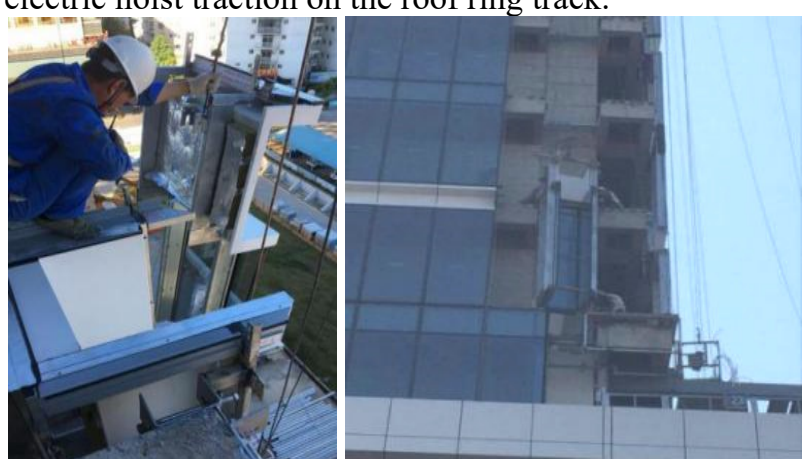

(a) unit body mount (b) unitbody lifting

Fig.3. Alien unit body lifting

\subsection{The loading and geling process}

After lifting the unit curtain wall system to the specified position, it is necessary to mount it reliably on the building structure and glue treatment, and the curtain wall and the main structure of the hanging mainly rely on the transfer part to achieve.

In the main structure construction process, according to the results of measuring the release line, it is found that the pre-buried groove-type buried parts, grooveburied parts center coincide with the curtain wall grid line. Then install the T-bolt, U-type transfer part, stainless steel screw, which can be adjusted according to the construction deviation of the previous process in the horizontal direction along the grooved buried notch. The vertical dimensions of the U-turning part can be adjusted through the elliptical hole, and the stainless steel screw depth dimensions can be adjusted through the transfer slip holes, confirming that they are fixed correctly and are corrosion-proof. 


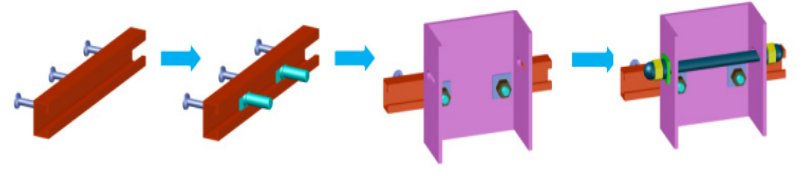

Fig.4. Transfer system installation process

The side and façade of the U-type transfer part are open oval holes, which can be in the depth direction and high degree direction has a small amount of room for adjustment. The length direction can be sliding by the groove buried parts slide, which can reduce the impact of buried parts construction error. The steel hanging ear side welding has an elonger nut, with hexagonal top wire, and after the plate is mounted, the error can be further adjusted according to the measurement results along the screw direction and height direction.

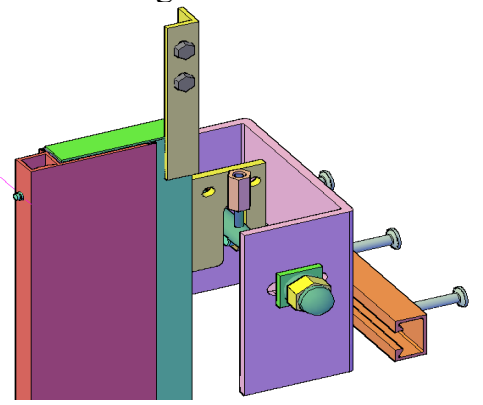

Fig.5. Transfers and column mountings

Afrter the Unit plate mounting completed, the indoor cover plate is instaled on the rear column, and the cover plate material is powder sprayed aluminum profile. First install the positioning card slot, and then fasten the inner cover plate. The façade vertical seams are glued by hanging basket operation, and neutral building silicone weather-resistant sealant is selected.

\section{Waterproof and ventilated}

After the curtain wall system is installed, the unit plate layer needs to be waterproof treatment:

(1) The "L-shaped" bending aluminum plate between the plates is installed, the length is $200 \mathrm{~mm}$, and the interface position between the plates is covered. The cross joint position is closed for the same water path as the beam. The weathering sealant compresses the contact point around the plate.

(2) Laying custom triple ethyl propylene rubber strip, rubber strip and aluminum profile on the beam are through the opening mold to form a biting port. T, the use of bite-in port fixed adhesive strip, auxiliary weatherresistant sealant are together by fixed to bond adhesive strip and beam .

(3) Two pieces of $20 * 150 * 200 \mathrm{~mm}$ foamed EPDM are bonded at the contact position of the transverse joint plates. When the upper plate is mounted, it is extruded to form a dense joint. After the external water enters the transverse joint, it can be discharged by the drainage path.

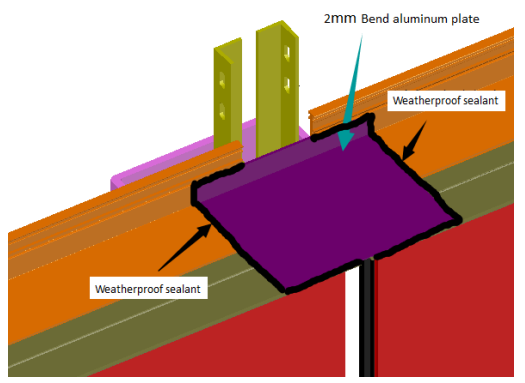

Fig.6. . "L-type" folded aluminum plate

(4) The cross-seam position between the upper and lower plates is used as the intake channel, and the cavity is reserved in the lower beam of the unit body to install a custom openable natural ventilator, and the lower beam aluminum profile is punched in spacing to ensure smooth ventilation path. Ventilation must meet two conditions:

(5) The air path must be bottom-up to prevent water from entering.

By pressure difference between use of the building and outdoor air, the region's pressure of strong air can be changed into the pressure of small air flow, which has the ventilation function.

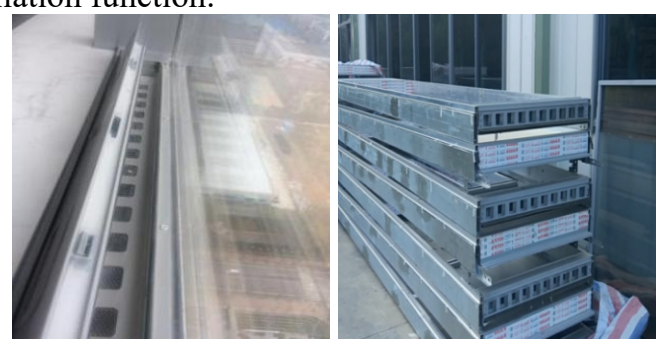

(a) opens the vent

(b) of the aluminumprofile punched by the ventilation path

Fig.7. Ventilation measures diagram

\section{Conclusions}

China is a big country in the production and use of curtain walls. However, the existing curtain wall system is mostly made of aluminum profiles. In construction, considering the weak strength of aluminum itself, it is usually known to increase the amount of aluminum per unit area of curtain wall to enhance the carrying capacity of curtain wall frame, resulting in higher construction costs. By optimizing the design, the system puts forward the "steel-aluminum hybrid curtain wall" based on the concept of rigid softness on the basis of the traditional all-steel and all-aluminum curtain walls. Steel carries weight and aluminum structure controls shape to find the steel aluminum balance of the "golden split point." Based on this, the study mainly has the following main conclusions:

(1) The curtain wall system unit plate skeleton is made of steel column and aluminum profile, which has high steel structure strength, and convenient docking, and mainly plays the role of carrying and controlling the shape;

(2) All unit plates are processed and assembled in the factory with high assembly accuracy and easy control of 
processing quality. When used for the overall lifting of the site, the installation is simple and the adjustment is convenient, which can effectively improve construction efficiency, shorten the construction period and save costs.

(3) The advance installation of the ropeway, the use of roof ring track and hoist to the unit plate overall lifting, transport to the installation floor using the track of the electric hoist traction horizontal direction in place, can effectively avoid the wind load caused by adverse shaking and rotation, and greatly reduce the risk of highaltitude operation.

(4) Considering that the steel aluminum curtain wall has both mechanical and aesthetic characteristics, it can better carry and control the shape.

(5) The 21 st century is the beginning of the age of intelligence. Predictably, there will be a huge market for curtain wall industry in the future, which will be towards intelligent development. With the Internet of Things and computer systems, light, temperature and air in the curtain wall system will be intelligently adjusted. Besides, the curtain wall system can improve the construction safety and waterproof performance, reduce the cost of materials, and provide an effective idea for the research and development of intelligent curtain wall.

\section{Acknowledgments}

This work was funded by Strategic Priority Research Program of the Chinese Academy of Sciences (No.XDA13010201) and the National Natural Science Foundation of China (Nos.41877267 , 41372316). Specially, the authors highly appreciate the critical and constructive comments from the three reviewers and editors.

\section{References}

1. Lin Xingui An exploration of the design and optimization of the structure of the curtain wall of the building China Residential Facilities, 2021, (03): 79-80

2. Li Xiaoyan Research on the construction technology of the exterior wall project of the building Sichuan Cement, 2021, (04): 234-235

3. Tai Deliang Frame glass curtain wall column optimization measures . . Doors and Windows, 2018, (01): $13-15$ plus 21

4. Hong ideal Reflections on the quality control and installation technology of glass curtain wall construction Urban Architecture, 2020, 17 (36): 9294

5. Liu Yonghua Application of the assembly construction technology of frame curtain wall keel unit . . . . Construction . . 2021,43 (02):205-208

6. Edge View Full, Li Qiang, Qiu Quan Slip-type Unit curtain wall waterproofing principle and water leakage analysis of Chinese buildingwaterproofing . 2019, (07):29-32

7. Zhu Wei, Lu Tong Steel-aluminum combination
Unit curtain wall construction technology . . Construction Technology, 2019, 48 (12): 118-121

8. Zeng Guangchun Ultra-high-rise building unit curtain wall construction technology . . Home, 2019, (11): 123-124

9. Zhao Xi'an JGJ102-2003The design section of the Glass Curtain Wall Engineering Technical Specification introduces the . Building Science, 2004, (03): 1-7

10. Liang Ronghai, Huang Wei To explore the key points of glass curtain wall construction technology in architectural decoration engineering Building materials and decoration, 2020, (02): 5-6

11. Zhong Songyi. Glass curtain wall construction technology in construction decoration works . . China Construction Metal Structure, 2020, (09): 114-115

12. Zheng Lidong. Steel-aluminum combination The technical points of the construction of the glass curtain wall . . Building materials and decoration, 2016, (03): 52-53

13. Zhang Lei. Study on the interface between the design and construction of the modular curtain wall Real Estate, 2019, (22): 29

14. Wu Jianwen . Asakusa steel aluminum combination curtain wall structure .. Doors and Windows, 2016, (04): 1-2.JC/T 882-2001, curtain wall glass seam with sealant. 